\title{
Serum IgM Monoclonal Gammopathy of Less than 30g/L
}

National Cancer Institute

\section{Source}

National Cancer Institute. Serum IgM Monoclonal Gammopathy of Less than 30g/L. NCI

Thesaurus. Code C150567.

An abnormal laboratory test result indicating that a serum Ig M paraprotein

concentration is less than $30 \mathrm{~g} / \mathrm{L}$. 